\title{
EFEITO DO HIDROGEL NO CRESCIMENTO DE MUDAS DE Eucalyptus benthamii SUBMETIDAS A DIFERENTES FREQUÊNCIAS DE IRRIGAÇÃO
}

\author{
Dionéia Felippe ${ }^{1 *}$, Marcio Carlos Navroski ${ }^{2}$, Jean Alberto Sampietro ${ }^{2}$, Taciana Frigotto ${ }^{1}$, \\ Jackson Adriano Albuquerque ${ }^{3}$, Clenilso Sehnen Mota $^{4}$, Mariane Oliveira Pereira ${ }^{2}$ \\ ${ }^{1}$ Universidade do Estado de Santa Catarina, Programa de Pós Graduação em Engenharia Florestal, Lages, Santa Catarina, Brasil - \\ *dioneia.felippe@gmail.com; tacianafrigotto@gmail.com \\ ${ }^{2}$ Universidade do Estado de Santa Catarina, Departamento de Engenharia Florestal, Lages, Santa Catarina, Brasil - \\ marcio.navroski@udesc.br; engsampietro@gmail.com; maripereira.florestal@gmail.com \\ ${ }^{3}$ Universidade do Estado de Santa Catarina, Departamento de Solos, Lages, Santa Catarina, Brasil - jackson.albuquerque@udesc.br \\ ${ }^{4}$ Universidade do Estado de Santa Catarina, Programa de Pós Graduação em Produção Vegetal, Lages, Santa Catarina, Brasil - \\ csm.sehnen@gmail.com
}

Recebido para publicação: 13/11/2015 - Aceito para publicação: 09/05/2016

\begin{abstract}
Resumo
A adição de polímeros hidroretentores visa aumentar a capacidade de retenção de água no solo para as mudas, propiciando melhor qualidade e maior sobrevivência no campo. Objetivou-se neste estudo avaliar o efeito do uso do hidrogel no plantio de mudas de Eucalyptus benthamii em vasos, relacionados com diferentes manejos hídricos, buscando fornecer informações sobre a eficiência do hidrogel simulando condições de campo. Foram utilizadas mudas de aproximadamente $25 \mathrm{~cm}$ de altura plantadas em vasos preenchidos com 4,5 L de solo. O experimento foi realizado em DIC, em esquema fatorial $2 \times 3$, com ausência e presença de hidrogel relacionados aos manejos hídricos (irrigação somente no plantio, a cada 3 e 6 dias). Do plantio até o $47^{\circ}$ dia foram realizadas avaliações da sintomatologia do estresse hídrico, teores de clorofila e trocas gasosas. Por fim, avaliou-se o desenvolvimento das mudas através da biomassa seca radicular e da parte aérea, além da determinação da curva de retenção de água. O hidrogel proporcionou um aumento na retenção de água, consequentemente um atraso nos sintomas de estresse hídrico, influenciando positivamente o teor de clorofila e trocas gasosas. Foi visível a recuperação da transpiração $(E)$, assimilação líquida de $\mathrm{CO}_{2}(A)$, condutância estomática $\left(g_{s}\right)$ e transpiração $(E), 24 \mathrm{~h}$ após a irrigação. Avaliações da biomassa seca demonstraram que os tratamentos com a presença do hidrogel apresentaram um melhor desenvolvimento das mudas.

Palavras-chave: Eucalipto; polímero hidroretentor; déficit hídrico.
\end{abstract}

\begin{abstract}
Water-absorbing polymer saim to increase the water retention capacity of the soil for the seedlings, providing better quality. The aim of this study was to evaluate the effect of using the hydrogel in planting seedlings of Eucalyptus benthamii in pots, related to different water management, seeking to provide information on the hydrogel efficiency simulating field conditions. Seedlings about $25 \mathrm{~cm}$ planted in pots filled with $4.5 \mathrm{~L}$ of soil were used. The experiment was conducted in DIC in factorial $2 \times 3$, with absence and presence of hydrogel related to water management (irrigation only in the planting, every 3 and 6 days). Planting until the $47^{\text {th }}$ day were evaluated for the symptoms of water stress, chlorophyll content and gas exchange. Finally, was evaluated the development of the plants through the root dry weight and shoot, as well as determining the water retention curve. The hidrogel resulted in an increase in water retention, thus a delay in symptoms of water stress, positively influencing the chlorophyll content and gas exchange. The recovery of, gs, and $24 \mathrm{~h}$ after irrigation was visible. Assessments of dry biomass showed that the treatments with the presence of hydrogel showed a better development of seedlings.

Keywords: Eucalyptus; hidroretentor polymer; water deficit.
\end{abstract}

\section{INTRODUÇÃOO}

O setor brasileiro de árvores plantadas é responsável por $91 \%$ de toda a madeira produzida para fins industriais no País, ocupando uma área de 7,74 milhões de hectares, o que corresponde a 0,9\% do território nacional, sendo que os demais $9 \%$ vem de florestas nativas legalmente manejadas. Dentre as espécies florestais mais cultivadas no Brasil, destaca-se as do gênero Eucalyptus, ocupando hoje 5,56 milhões de hectares da área de árvores plantadas representando 71,9\% do total (IBÁ, 2015).

No entanto, as espécies deste gênero que apresentam importância econômica para as regiões mais frias do Brasil, constituem um grupo muito restrito limitando assim a expansão de seu cultivo. Pertencente à família

FLORESTA, Curitiba, PR, v. 46, n. 2, p. 215 - 225, abr. / jun. 2016.

Felippe, D. et al.

ISSN eletrônico 1982-4688

DOI: $10.5380 /$ rf.v46i2.43920 
Myrtaceae, subfamília Leptospermoideae encontra-se Eucalyptus benthamii, que embora apresente características distintas, faz parte do mesmo grupo botânico do Eucalyptus viminalis Labill. (HIGA; PEREIRA, 2003). Essa espécie é considerada vulnerável ao desaparecimento na região de ocorrência natural, correspondente ao curso do Rio Nepean, a oeste de Sydney, Austrália (BUTCHER et al., 2005).

A madeira do Eucalyptus benthamii é moderadamente dura com densidade básica de $0,47 \mathrm{~g} / \mathrm{cm}^{3}$, cerne e alburno distintos, sendo o cerne de cor marrom-avermelhada e o alburno rosado. Apresenta textura fina a média, grã-irregular, cheiro e gosto imperceptíveis e superfície levemente brilhante (NISGOSKI et al., 1998). Apresenta taxas de crescimento elevadas tendo exibido capacidade de crescer em diversos sítios, incluindo aqueles sujeitos a secas e geadas (FAO et al., 2004). Para a implantação de florestas produtivas é necessária uma combinação de vários fatores, tais como materiais genéticos adaptados ao local, condições edafoclimáticas favoráveis, manejo adequado e mudas de alto padrão de qualidade (DAVIDE, FARIA, 2008). No entanto, a influência das variáveis ambientais no crescimento de povoamentos de eucalipto é notória, dentre elas se destacam a precipitação pluviométrica, a evapotranspiração potencial, a temperatura mínima e a temperatura máxima (MAESTRI, 2003). Conforme afirmaram Souza et al. (2006), a relação entre a disponibilidade e a produtividade florestal é concernente aos efeitos diretos e indiretos da deficiência de água no crescimento das árvores.

Portanto, a irrigação de mudas de espécies florestais durante o plantio e nas primeiras semanas da implantação é considerada uma operação muito importante em plantios comerciais, principalmente nas épocas mais secas do ano, influindo diretamente na sobrevivência e desenvolvimento das mesmas (BUZZETTO et al., 2002). Como alternativa surge a utilização de hidroretentores como condicionadores de umidade no solo. Tratase de um polímero que auxilia principalmente na retenção e disponibilidade de água para as mudas recémplantadas (AZEVEDO, 2000).

Gonçalves et al. (2004) afirmam que este produto também contribui para a viabilização do plantio o ano todo, que não se torna mais dependente das variações climáticas observadas ao longo do ano. Como possibilitam a retenção de água e a sua liberação de maneira gradativa para a planta, podem aumentar a eficiência da irrigação e diminuir o risco da ocorrência de falhas durante o estabelecimento do povoamento florestal.

Neste sentido, o objetivo deste trabalho foi avaliar o efeito do hidrogel no plantio de mudas de Eucalyptus benthamii em vasos, relacionados com diferentes manejos hídricos, buscando fornecer informações sobre a eficiência do uso do hidrogel a campo simulado em ambiente controlado.

\section{MATERIAIS E MÉTODOS}

O experimento foi conduzido no viveiro florestal da Universidade Estadual de Santa Catarina, localizado sob as coordenadas $27^{\circ} 47^{\prime} 33.62^{\prime \prime S}$ e 50¹8'4.60"W, com altitude de aproximadamente 900 metros. De acordo com a classificação de Köppen o clima do município de Lages, SC é mesotérmico úmido com verão ameno (Cfb-temperado). A temperatura média anual é de $15^{\circ} \mathrm{C}$ e a precipitação média anual vai de 1300 a $1500 \mathrm{~mm}$.

As mudas de Eucalyptus benthamii utilizadas foram de origem seminal, que após estarem com um desenvolvimento adequado para o plantio a campo, ou seja, altura próxima a $25 \mathrm{~cm}$ e no mínimo $2 \mathrm{~mm}$ de diâmetro de coleto, conforme recomendado por Wendling e Dutra (2010), foram transferidas para os vasos contendo solo da região, classificado como Cambissolo Húmico alumínico.

Para simular a condição de campo, foram usados vasos de polietileno com $5 \mathrm{~L}$ de capacidade, onde foi utilizado 4,5 L do solo previamente destorroado e seco. Depois de preenchidos os vasos, o solo foi molhado até a capacidade de campo (aproximadamente $1.500 \mathrm{~mL}$ por vaso) em todos os recipientes.

Foi realizada a abertura de uma cova manual de aproximadamente $300 \mathrm{~cm}^{3}$ no centro de cada vaso para a realização do plantio. Nos tratamentos utilizando o hidrogel foram adicionados $250 \mathrm{~mL}$ na forma já hidratada, antes da realização do plantio da muda. A hidratação foi realizada com água corrente de poço e ocorreu meia hora antes do plantio, sendo que a dosagem do hidrogel utilizada foi de $3 \mathrm{~g} \mathrm{~L}^{-1}$. Após a abertura da cova para o plantio, preenchidas ou não com o hidrogel, foi realizado o plantio das mudas de Eucalyptus benthamii.

Após o plantio, além dos $1500 \mathrm{~mL}$ para umedecer o solo, foram adicionadas $250 \mathrm{~mL}$ de água para cada vaso para os tratamentos sem o hidrogel, de modo a compensar o volume de água a ser adicionado via hidrogel. Para os tratamentos com irrigações foram utilizados $250 \mathrm{~mL}$ de água em cada vaso seguindo a frequência determinada de acordo com cada tratamento.

$\mathrm{O}$ experimento foi realizado em delineamento inteiramente casualizado, em esquema bifatorial, em que os níveis do fator "A" referiram-se a presença ou ausência de hidrogel e, os níveis do fator "B", o manejo hídrico - irrigação (somente no plantio, intervalos de 3 e 6 dias entre cada irrigação). Utilizou-se 10 repetições compostas por uma planta cada repetição. 


\section{Análises Fisiológicas}

Depois do plantio até o $47^{\circ}$ dia, diariamente foramrealizadas avaliações da sintomatologia do estresse hídrico, teores de clorofilae verificação da temperatura da casa de vegetação. Para a sintomatologia visual foi adotado o critério de análise, conforme Navroski et al. (2014), sendo anotado o número de dias em que a planta permanecia em cada condição: SEM-dias sem sintomas (planta turgida, visualmente vigorosa, sem indícios de déficit hídrico; SLM- dias com sintomas leves de murcha; SMM- dias com sintomas moderados (planta em ponto de murcha permanente, com ápice escurecido e curvado); SSM- dias com sintomas severos de murcha (folhas secasse/ou em abscisão). Para a sobrevivência foiadotado o código PPV- número de dias que a planta permaneceu viva.

Para determinação do teor de clorofila foi utilizado o medidor portátil de clorofila SPAD-502 (Minolta Camera Co. Ltd.), determinando em duas folhas completamente expandidas da porção mediana da copa de cada planta da unidade experimental, sendo estas folhas identificadas para posterior avaliações, e as medições realizadas em duasposições da folha (lados opostos na folha). Das quatro leituras, calculou-se a média para ambas as folhas amostradas, utilizando-se o próprio medidor. As medições ocorriam em 10 repetições de todos os tratamentos sempre no período que antecedesse a irrigação.

Já as avaliações de trocas gasosas foram realizadas apenas nos tratamentos com a presença e ausência do hidrogel na frequência de 3 dias de irrigação, não sendo possível avaliar os demais tratamentos, devido a mortalidade que ocorreu gradativamente no decorrer do experimento. Estas avaliações foram realizadas com o auxílio de um medidor portátil de fotossíntese (modelo Li-6400xt), foi determinado os valores de assimilação líquida de $\mathrm{CO}_{2}(A)$, condutância estomática $\left(g_{s}\right)$, transpiração $(E)$, relação entre a concentração intercelular e atmosférica de $\mathrm{CO}_{2}(\mathrm{Ci} / \mathrm{Ca})$ e eficiência no uso da água (WUE). Dentro da casa de vegetação, as plantas receberam, durante a mensuração, irradiância de aproximadamente $900 \mathrm{mmol}$ de fótons $\mathrm{m}^{-2} \mathrm{~s}^{-1}$. Esse valor foi determinado pela curva de saturação luminosa medida para o eucalipto, situando-se entre 800 e $1.000 \mathrm{mmol}$ de fótons $\mathrm{m}^{-2} \mathrm{~s}^{-1}$, conforme Silva et al. (1998). As avaliações de trocas gasosas foram realizadas imediatamente antes e $24 \mathrm{~h}$ após a irrigação e 43 dias após o transplante e início da irrigação intermitente. As avaliações em ambos os dias iniciaram aproximadamente as $8 \mathrm{~h}: 00 \mathrm{~min}$.

\section{Massa seca}

Para finalizar as avaliações, aproximadamente aos 48 dias, através de um método destrutivo, procedeuse a coleta manual da massa da parte aérea e radicular das plantas. A coleta foi realizada apenas nos tratamentos onde receberam irrigação intermitente, ou seja, nas frequências de 3 e 6 dias, independente da ausencia e a presença. Estas foram separadas e acondicionadas em sacos de papel mantidos em estufa com circulação forçada de $\operatorname{ar}\left(65 \pm 3{ }^{\circ} \mathrm{C}\right)$ até atingirem massa constante, após foram efetuadas pesagens para determinação dos teores de matéria seca dos componentes em balança de precisão $(0,01 \mathrm{~g})$.

\section{Curva de retenção de água disponível}

Para determinação da curva de retenção de água disponível, foram utilizadas 5 amostras de solo com a presença de hidrogel incorporado ao substrato e 5 amostras com a ausência do hidrogel, totalizando 10 amostras coletadas em anéis cilíndricos com aproximadamente $50 \mathrm{~cm}^{3}$ de modo a ser preservado o máximo da estrutura original do solo.

No laboratório, as amostras com estrutura preservada foram inicialmente saturadas por capilaridade por 24 horas, com uma lâmina de água de aproximadamente $3 \mathrm{~cm}$ e depois pesadas. Em seguida submetidas em coluna de areia obtendo-se as umidades nas tensões de equilíbrio de 1, 6 e $10 \mathrm{kPa}$. (REINERT; REICHERT, 2006) e nas tensões de 33 e 100, 500, 1000 e 1500 kPa em câmaras de pressão de Richards (KLUTE, 1986). A umidade volumétrica das amostras foi obtida pela relação entre a quantidade de água retida em determinada tensão e o volume do cilindro de coleta, sendo que, para isso, ao final as amostras foram levadas à estufa por cerca de dois dias, onde obteve-se o peso seco de solo e também a densidade (Ds) (BLAKE; HARTGE, 1986).

Com os valores de umidade nas tensões de $1,6,10,33,100,500,1000$ e $1500 \mathrm{kPa}$, foi realizado o ajuste da curva de retenção de água no solo (CRA), utilizando o modelo de van Genuchten (1980) por meio do programa computacional SWRC (Soil Water Retention Curve) (DOURADO-NETO et al., 2001).

\section{Análise estatística}

Após confirmada a normalidade e a homogeneidade dos dados das variáveis analisadas foi realizada análise de variância paramétrica ao nível de $5 \%$ de probabilidade de erro. Quando o valor de "F" foi significativo, os tratamentos qualitativos tiveram suas médias comparadas por meio do teste Scott-Knott ou teste t, ao nível de 5\% de probabilidade de erro. O pacote estatístico SISVAR (FERREIRA, 2011) foi utilizado para a análise estatística dos dados. Para o desenvolvimento dos gráficos foi utilizado o Origin Pró 9 e o Grapher 8. 


\section{RESULTADOS E DISCUSSÕES}

\section{Análises fisiológicas}

Não foi observada interação entre o uso de hidrogel e a frequência de irrigação na avaliação de plantas com sintomas leves e moderados, independente da frequência de irrigação. Com a presença do hidrogel as mudas de Eucalyptus benthamii permaneceram mais dias sem o aparecimento do estresse hídrico, retardando em todos os níveis o aparecimento de sintomas, comparado com a ausência do mesmo, onde os sintomas apareceram bem antes (Tabela 1). O uso de irrigação apresentou efeito esperado, sendo que em menor intervalo, ou seja, na frequência de três dias, houve atraso no aparecimento de sintomas. No final da avaliação ainda foram encontradas plantas vivas, porém não foram encontradas plantas sem estresse hídrico, independente do uso ou não do hidrogel.

Tabela 1. Média dos resultados de duração dos sintomas de estresse hídrico nas plantas, em dias, avaliado a partir do plantio até o $46^{\circ}$ dia após o plantio de Eucalyptus benthamii em vasos, em função da presença ou ausência de hidrogel e diferentes frequências de irrigação.

Table 1. Average of the duration of symptoms of water stress in plants, in days, judged from the planting to the $46^{\text {th }}$ day after planting Eucalyptus benthamii in pots, depending on the presence or absence of hydrogel and different frequency of irrigation.

\begin{tabular}{|c|c|c|c|c|c|}
\hline \multirow{3}{*}{ Variável } & \multirow{3}{*}{ Hidrogel } & \multicolumn{3}{|c|}{ Aparecimento dos sintomas de estresse (dias) } & \multirow{3}{*}{ Médias } \\
\hline & & \multicolumn{3}{|c|}{ Frequência de Irrigação } & \\
\hline & & Plantio & 6 DIAS & 3 DIAS & \\
\hline \multirow{3}{*}{ SEM** } & Ausência & $26,7 \mathrm{Ca}^{*}$ & $34,9 \mathrm{Bb}$ & $42,6 \mathrm{Aa}$ & \multirow{3}{*}{$\begin{array}{l}35,5 \\
38,8\end{array}$} \\
\hline & Presença & $27,1 \mathrm{Ba}$ & $45,4 \mathrm{Aa}$ & $43,9 \mathrm{Aa}$ & \\
\hline & Média & 26,9 & 40,1 & 43,3 & \\
\hline \multirow{3}{*}{ SLM } & Ausência & 31,8 & 42,8 & 44,5 & \multirow{3}{*}{$\begin{array}{l}40,0^{\mathrm{ns}} \\
41,3^{\mathrm{ns}}\end{array}$} \\
\hline & Presença & 32,4 & 46,0 & 45,0 & \\
\hline & Média & $32,2 \mathrm{~B}$ & $44,4 \mathrm{~A}$ & $44,8 \mathrm{~A}$ & \\
\hline \multirow{3}{*}{ SMM } & Ausência & 35,6 & 45,1 & 44,8 & \multirow{3}{*}{$\begin{array}{r}42,0 \mathrm{~b} \\
43,1 \mathrm{a}\end{array}$} \\
\hline & Presença & 37,5 & 46,0 & 46,0 & \\
\hline & Média & $36,3 \mathrm{~B}$ & $45,5 \mathrm{~A}$ & $45,40 \mathrm{~A}$ & \\
\hline \multirow{3}{*}{ SSM } & Ausência & $38,3 \mathrm{bB}$ & $46 \mathrm{aA}$ & $45 \mathrm{aA}$ & \multirow{3}{*}{$\begin{array}{l}43,3 \\
44,9\end{array}$} \\
\hline & Presença & $42,9 \mathrm{aB}$ & $46,2 \mathrm{aA}$ & $46 \mathrm{aA}$ & \\
\hline & Média & 40,7 & 46,1 & 45,5 & \\
\hline \multirow{3}{*}{ PPV } & Ausência & $38,3 \mathrm{bB}$ & $45,5 \mathrm{aA}$ & $45,0 \mathrm{aA}$ & \multirow{3}{*}{$\begin{array}{l}43,1 \\
44,9\end{array}$} \\
\hline & Presença & $42,9 \mathrm{aB}$ & $46,5 \mathrm{aA}$ & $46,0 \mathrm{aA}$ & \\
\hline & Média & 40,6 & 46,0 & 45,5 & \\
\hline
\end{tabular}

Analisando as frequências de irrigação para classe dias sem sintomas, os dados obtidos mostraram que houve interação $(p<0,05)$ entre os fatores das variáveis avaliadas, porém a diferença estatística foi somente nos intervalos maiores de irrigação, ou seja, somente no plantio e na frequência de 6 dias, não sendo observado efeito da presença ou ausência do hidrogel no uso da irrigação mais frequente (3 dias). Já na presença de hidrogel, a frequência de 6 dias, mostrou um ganho relativamente alto sem o aparecimento de sintomas, comparando com a ausência deste polímero, elevando o tempo para o aparecimento de estresse comparando com a irrigação somente no plantio, demonstrando que a utilização deste polímero responde positivamente a escassez de água no solo.

Para as classes dias com sintomas leves de murcha, apesar de não haver interação entre os fatores das variáveis avaliadas, a diferença estatística foi observada também apenas no plantio. Quanto a irrigação na presença deste polímero e com a frequência de seis dias, os resultados obtidos mostraram um ganho sem o aparecimento de sintomas leves. Já a não utilização do mesmo, mesmo com a irrigação, houve uma ocorrência acelerada desses sintomas. Cabe salientar que neste nível de estresse as mudas ainda apresentam total condição fisiológica de se recuperarem em caso de ocorrência de chuva.

O aparecimento da classe de Sintomas Moderados de Murcha (SMM), onde a planta já encontra-se próximo ao ponto de murcha permanente, seguiu um comportamento similar ao sintoma leve, havendo um retardamento do estresse quando o hidrogel se fez presente. 
Considerando os sintomas severos de murcha, que segundo Navroski et al.(2014) nesse nível de estresse uma recuperação da planta com novas irrigações ou chuvas já é dificultada, o hidrogel continuou mostrando-se eficiente, sendo que houve um atraso em mais de seis dias no aparecimento desses sintomas quando se utilizou a irrigação somente no plantio em relação ao não uso do mesmo.

Estes resultados, foram semelhantes aos de Navroski et al. (2014), em que a utilização deste polímero respondeu positivamente a escassez de água no solo, possibilitando o retardamento dos sintomas de déficit hídrico, onde a maior influência ocorreu quando a irrigação foi efetuada em menor frequência.

É importante destacar que na implantação de florestas de Eucalyptus, normalmente, observa-se que o período mais crítico quanto à perda de mudas por falta de água é nos primeiros 20 dias após o plantio, período em que a planta está se estabelecendo e, com um sistema radicular ainda em formação (FERNÁNDEZ et al., 2010). Na implantação de um plantio a campo, pode-se supor que nos casos em que a irrigação é efetuada frequentemente, ou nos casos em que a frequência de chuvas é maior, o uso do polímero poderia ser descartado (NAVROSKI et al., 2015). Contudo, em condições com menor frequência de chuva, ou fazendo-se irrigações mais espaçadas, o uso do polímero pode ser recomendado.

Na avaliação do número de dias em que as plantas permaneceram vivas, percebeu-se que o uso do hidrogel somente apresentou diferença quando a irrigação ocorreu apenas no plantio (Tabela 1). Neste caso, com a presença do hidrogel no solo, obteve-se um aumento de aproximadamente 5 dias em que permaneceram vivas, fazendo-se o uso deste polímero. Nas frequências de irrigações de 3 e 6 dias, não foi observado efeito significativo como seu uso, mas verificou-se um aumento no número de dias em que as plantas permaneceram vivas.

$\mathrm{O}$ aumento de dias em que as plantas permaneceram vivas com o uso do polímero também foi observado por Lopes et al. (2010) em estudo com Eucalyptus urograndis, que segundo os autores, com o uso do polímero as plantas permaneceram vivas em média por 34,7 dias contra 26,2 dias na ausência. Os autores destacam ainda que o uso do polímero hidroretentor pode reduzir o número de replantios, e consequentemente dos custos com implantação, justificando os gastos com o uso do polímero.

No uso de irrigações pós-plantio não foi observado efeito significativo do uso do hidrogel, isto pode indicar que o uso do hidrogel é benéfico no retardamento da mortalidade das mudas quando não se faz o uso de irrigações frequentes ou a mesma e realizada apenas no plantio, permitindo um ganho de alguns dias na espera da ocorrência da chuva.

Resultados semelhantes a este trabalho foram encontrados por Navroski et al.(2014), onde afirmam que com o uso de irrigações mais frequentes as mudas têm uma sobrevivência maior em dias, diminuindo quando se fez uso da frequência de seis dias. A irrigação, quando realizada somente no plantio, ocasionou uma mortalidade muito mais precoce das mudas, diferenciando das irrigações pós-plantio.

Em relação as análises fotossintéticas realizadas aos 45 dias após implantação do experimento, avaliando a eficiência do hidrogel antes da irrigação e 24 h hora após, na ausência ou na presença deste polímero no solo de cultivo, pode-se observar efeito direto nas trocas gasosas desta espécie (Tabela 2).

Tabela 2. Assimilação líquida de $\mathrm{CO}_{2}(A)$, condutância estomática $(g)$, transpiração $(E)$, relação entre a concentração intercelular e atmosférica de $\mathrm{CO}_{2}(\mathrm{Ci} / \mathrm{Ca})$ e eficiência no uso da água $(W U E)$ em Eucalyptus benthamii antes e $24 \mathrm{~h}$ horas após irrigação e com ausência ou presença de hidrogel no solo de cultivo.

Table 2. Assimilation $\mathrm{CO}_{2}(\mathrm{~A})$, stomatal conductance (gs), transpiration (E), relationship between intercellular and atmospheric $\mathrm{CO}_{2}$ concentration $(\mathrm{Ci} / \mathrm{Ca})$ and efficient use of water (WUE) in Eucalyptus benthamii before and 24 hours after irrigation and presence or absence the hydrogel in the soil.

\begin{tabular}{|c|c|c|c|c|c|c|}
\hline Época & Hidrogel & 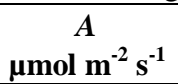 & $\begin{array}{c}g_{s} \\
\mathrm{~mol} \mathrm{~m}^{-2} \mathrm{~s}^{-1}\end{array}$ & $\begin{array}{c}E \\
\mathrm{mmol} \mathrm{m}^{-2} \mathrm{~s}^{-1}\end{array}$ & $\begin{array}{c}\mathrm{Ci} / \mathrm{Ca} \\
\mathrm{mol} \mathrm{mol}^{-1}\end{array}$ & 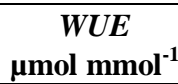 \\
\hline Antes & Com & $1,74 \mathrm{Aa}^{*}$ & $0,013 \mathrm{Aa}$ & $0,225 \mathrm{Aa}$ & $0,527 \mathrm{Ba}$ & 6,26Aa \\
\hline Antes & Sem & 2,97Aa & $0,019 \mathrm{Aa}$ & $0,236 \mathrm{Aa}$ & $0,349 \mathrm{Aa}$ & $12,78 \mathrm{Bb}$ \\
\hline Após & Com & $9,50 \mathrm{Ab}$ & $0,103 \mathrm{Ab}$ & $1,623 \mathrm{Ab}$ & $0,562 \mathrm{Aa}$ & 5,92Aa \\
\hline Após & Sem & $8,14 \mathrm{Ab}$ & $0,083 \mathrm{Ab}$ & $1,231 \mathrm{Ab}$ & $0,541 \mathrm{Aa}$ & $6,76 \mathrm{Aa}$ \\
\hline
\end{tabular}

Com base nos resultados, o uso do hidrogel, no geral não resultou diferença significativa, observou-se, porém que nas avaliações antes da irrigação, tratamentos sem hidrogel apresentaram os melhores valores para todas as variáveis analisadas. Este fato pode ser explicado pela planta desenvolver um mecanismo de tolerância à seca, ao nível celular onde ocorre a produção e/ou acúmulo de solutos osmoticamente ativos (prolina, glutamina, betaína, sorbitol e manitol), processo conhecido como ajustamento osmótico ou osmorregulação, a fim de manter o turgor e equilíbrio do potencial hídrico na célula (NUNES, 2007). Para Serraj e Sinclair (2002), o ajuste

FLORESTA, Curitiba, PR, v. 46, n. 2, p. 215 - 225, abr. / jun. 2016.

Felippe, D. et al.

ISSN eletrônico 1982-4688

DOI: $10.5380 /$ rf.v46i2.43920 
osmótico permite a sobrevivência da planta em deficiência hídrica, mas não mantêm o crescimento e a produtividade da planta.

Para Lambers et al.(2008), a regulação estomática possui basicamente dois componentes, um ligado à pressão de turgor das células guardas, portanto um controle mecânico, e outro ligado à concentração de $\mathrm{CO}_{2}$ intercelular (bioquímico). Nesse último caso, uma redução na concentração interna de $\mathrm{CO}_{2}$ estimularia a abertura estomática.

Foi visível a recuperação de $A, E$ e $g_{s}, 24 \mathrm{~h}$ após a irrigação, demostrando que a limitação de $A$ provavelmente ocorreu devido a limitação estomática, dada a rápida recuperação. Os valores de $C i / C a$, se mantiveram praticamente inalterados após a irrigação. Os valores de $A / E$ apresentaram tendência de redução após a irrigação, ou seja, houve aumento na $A / E$ ao final do período pós-irrigação. Esses resultados evidenciaram que todos os processos fisiológicos da célula são direta ou indiretamente afetados pelo fornecimento de água. No entanto, Agaba et al. (2011), afirmam que a habilidade do hidrogel para reter e disponibilizar água mais lentamente pode favorecer a resiliência, ou seja, a habilidade de as mudas retornarem ao estado normal, após a ocorrência do estresse hídrico.

Os valores de WUE mantiveram seus valores superiores na ausência do hidrogel, tanto antes da irrigação quanto 24 horas após a mesma, sendo que este fato justifica-se por uma estratégia que a planta desenvolve para enfrentar o déficit hídrico, sendo na ausência do mesmo, mais eficiente no uso da água.

Segundo Souza et al.(2004), o controle da perda de água pelo fechamento estomático consegue manter elevado o potencial hídrico e o conteúdo relativo de água nas folhas. Como consequência, há restrições na condutância estomática e trocas gasosas, que reduz a taxa de transpiração e assimilação de $\mathrm{CO}_{2}$.

O estresse por deficiência hídrica é produzido tanto pela limitação de água no solo quanto por perda excessiva pela transpiração em relação à absorção feita pelas raízes, sendo esses processos influenciados por fatores ambientais e por características da própria planta (SANT' ANNA, 2009). A primeira e mais sensível resposta à deficiência hídrica está na diminuição da turgescência, por meio da qual ocorre o fechamento dos estômatos, a redução na fotossíntese e a diminuição do alongamento celular, principalmente em extensão (LARCHER, 2006).

A transpiração excessiva também pode comprometer a disponibilidade de água para os processos vitais da planta, principalmente quando se trabalha em situações em que a quantidade de água disponível é reduzida (CHAVES, 2001).

Segundo Pereira (2006), das inúmeras importâncias fisiológicas da água para o vegetal destacam-se: atua como reagentes e produtos da atividade fotossintética; fonte de elétrons, após a ativação da clorofila pela luz, para produzir energia química; meio de transporte de solutos e gases; afeta a divisão e o crescimento celular; influi na turgescência das raízes e, consequentemente, a sua penetração no solo; participa dos processos de abertura e de fechamento dos estômatos; afeta a viscosidade e a permeabilidade do protoplasma e a atividade das enzimas envolvidas; produto final da atividade respiratória; efeito resfriante, funcionando como tampão de temperatura; e afeta a translocação de assimilados.

\section{Teor de Clorofila}

O teor de clorofila das plantas de Eucalyptus benthamii em todos os tratamentos apresentou boa resposta ao uso do hidrogel, sendo que os maiores índices foram observados nos tratamentos com a presença deste polímero, como pode ser visualizado na figura 1. Estes resultados sugerem que a adição do polímero possivelmente diminua a perda de nutrientes por lixiviação, proporcionando assim maior taxa fotossintética devido a maiores teores de nitrogênio, sendo que este nutriente está diretamente ligado a maior taxa fotossintética da planta. Neste sentido o solo apresentando maior disponibilidade de água a taxa de mineralização da matéria orgânica aumenta em relação ao solo com umidade menor disponibilizando assim uma maior quantidade de nitrogênio para planta. Estes resultados podem ser explicados devido ao solo com maior retenção de água apresentar maior quantidade de nitrogênio na forma de nitrato na solução do solo sendo que este é absorvido mais facilmente por fluxo de massa.

Tohidi-Moghadam et al. (2009), estudando a resposta de seis genótipos de canola a estresse hídrico e a aplicação de hidrogel, observaram que a deficiência da água também reduziu o conteúdo de clorofila e que sob condições de campo, o hidrogel, aumentou o desempenho dos caracteres fisiológicos, sendo que, a deficiência de água e a ausência de hidrogel levaram a um decréscimo em todos os parâmetros avaliados. Segundo estes autores, esses resultados podem ser relacionados à redução da fotossíntese e também do conteúdo de clorofila. 


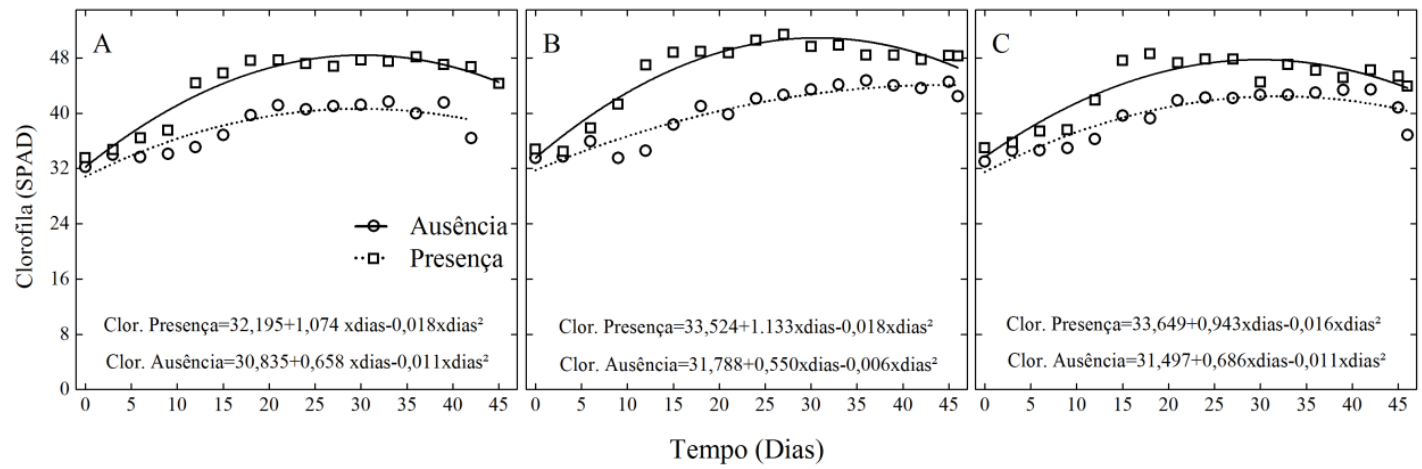

Figura 1. Teores de clorofila nas plantas em função da presença ou ausência de hidrogel e diferentes frequências de irrigação. A- Irrigação apenas no plantio; B- Irrigação a cada 6 dias; C- Irrigação a cada 3 dias.

Figure 1. Levels of chlorophyll in plants in the presence or absence of different frequencies hydrogel and irrigation. A- Irrigation only at planting; B- irrigation every 3 days; C- irrigation every six days.

\section{Massa seca}

Analisando a variável massa seca radicular, verificou-se que houve diferença significativa $(p<0,05)$, para a interação hidrogel e frequência de irrigação. Na frequência de 3 dias de irrigação, os tratamentos com e sem hidrogel, não tiveram diferença estatística. Já para a frequência de irrigação de 6 dias o tratamento com hidrogel foi superior ao sem hidrogel (Tabela 3).

Tabela 3. Médias de massa seca radicular (g) em mudas de Eucalyptus benthamii sob o uso de hidrogel e frequências de irrigação.

Table 3. Average dry root mass seedlings Eucalyptus benthamii hydrogel under usage and irrigation frequency.

\begin{tabular}{lccc}
\hline & \multicolumn{3}{c}{ Hidrogel } \\
\cline { 2 - 4 } Frequência & \multicolumn{2}{c}{ Com } & Sem \\
\hline 3 dias & $1,7 \mathrm{~g} \mathrm{aA}$ & $1,9 \mathrm{~g} \mathrm{aA}$ \\
6 dias & $1,46 \mathrm{~g} \mathrm{aA}$ & $0,87 \mathrm{~g} \mathrm{bB}$ \\
\hline
\end{tabular}

*Letras maiúsculas na linha e letras minúsculas na coluna iguais não diferem estatisticamente a $5 \%$ pelo teste t.

O uso do hidrogel mostrou-se eficiente no manejo de irrigação a cada 6 dias, sendo este período adequado para detectar a diferença de massa seca radicular quando comparado a ausência no uso desse polímero para a espécie Eucalyptus benthamii. Estes resultados foram semelhantes aos de Navroski et al. (2015), onde no estudo da influência do hidrogel no crescimento e no teor de nutrientes das mudas de Eucalyptus dunnii, maior dose de hidrogel proporcionou maior massa de raízes. Os autores atribuíram o resultado, a provavelmente maior disponibilidade de água e de nutrientes às mudas em desenvolvimento.

Esta afirmação é corroborada com Nicoletti et al. (2014), que estudando o efeito deste polímero no enraizamento e crescimento inicial de miniestacas do híbrido Eucalyptus urograndis, a massa seca de raízes apresentou boa resposta ao uso do mesmo. Os autores ainda citam que esta variável apresenta alta importância no desenvolvimento das plantas, pois mudas bem enraizadas apresentam maior capacidade de crescimento e maior potencial de sobrevivência a campo no momento do plantio. Segundo Haase (2008), mudas que apresentam maior massa seca radicular tendem a sobreviver melhor do que aquelas que possuem massa seca radicular inferior.

Avaliando a presença de hidrogel, dentro das frequências de 3 e 6 dias, não houve diferença significativa. Esses resultados indicam que independentemente do tempo de irrigação a utilização de hidrogel favoreceu o aumento da massa seca radicular das mudas. Já na ausência do hidrogel, houve diferença significativa entre as frequências, sendo que a de 3 dias teve maior massa seca radicular em relação à frequência de irrigação de 6 dias.

Para a variável massa seca da parte aérea a interação hidrogel e frequência de irrigação não foi significativa $(p>0,05)$. Entretanto, houve diferença significativa para os fatores principais (hidrogel e frequência de irrigação) (Tabela 4). Para o hidrogel, a presença deste representou massa seca da parte aérea superior em relação a ausência de hidrogel. Os resultados encontrados mostram a eficiência do hidrogel como condicionador de solo, no qual, além de aumentar a capacidade de armazenamento de água no solo, as variáveis analisadas (massa seca da raiz e da parte aérea), foram beneficiadas pela adição deste polímero.

FLORESTA, Curitiba, PR, v. 46, n. 2, p. 215 - 225, abr. / jun. 2016.

Felippe, D. et al.

ISSN eletrônico 1982-4688

DOI: $10.5380 /$ rf.v46i2.43920 
Tabela 4. Médias de massa seca da parte aérea de Eucalyptus benthamii em função do hidrogel e da frequência de irrigação.

Table 4. Dry mass medium shoots of Eucalyptus benthamii depending on the hidrogel and frequency of irrigation.

\begin{tabular}{ll}
\hline Hidrogel & MSPA $(\mathbf{g})$ \\
\hline Com & $2,93 \mathrm{a}^{*}$ \\
Sem & $1,77 \mathrm{~b}$ \\
\hline Frequências de irrigação & MSPA $(\mathrm{g})$ \\
3 dias & $2,83 \mathrm{a}^{*}$ \\
6 dias & $1,82 \mathrm{~b}$ \\
\hline *Medias seguidas de letras semelhantes não diferem estatisticamente a 5 \% pelo teste t.
\end{tabular}

Estes resultados foram semelhantes com os resultados encontrados no trabalho de Navroski et al. (2015), onde ao testar diferentes doses de hidrogel em Eucalyptus dunnii, houve um ganho expressivo de massa seca da parte aérea, próximo a dose de máxima eficiência técnica $\left(4,9 \mathrm{~g} \mathrm{~L}^{-1}\right)$ em comparação com a ausência de hidrogel ou o uso de doses muito baixas.

Taylor e Halfacree (1986), estudando o efeito dos hidrogéis na retenção de água e disponibilidade de nutrientes para Ligustrum lucidum Ait. observaram que as plantas cresceram e não necessitaram de maior frequência na irrigação, para o tratamento com o polímero, quando comparado com a testemunha. Estes autores indicam os possíveis fatores que podem ter influenciado no status nutricional das plantas cultivadas com o polímero: a) o nutriente passa mais tempo em solução no solo; b) redução da lixiviação; c) capacidade do polímero em trocar cátions; d) capacidade do polímero em quelatizar e manter o pH inalterado e) participação do polímero como fonte de nutrientes. Para a frequência de irrigação o intervalo entre irrigações de 3 dias proporcionou maior massa seca da parte aérea quando comparado a frequência de 6 dias (Tabela 4).

O uso do hidrogel incorporado ao substrato e associado a diferentes frequências de irrigação, influenciou positivamente o desenvolvimento das mudas de Eucalyptus benthamii, estes resultados podem ser atribuído a melhor retenção de água no solo promovida por ele.

\section{Curva de retenção de água disponível}

Verificou-se que o uso do hidrogel incorporado ao substrato provocou um aumento significativo na retenção de água no solo (Figura 2) quando comparado ao mesmo solo com a ausência deste polímero na curva de retenção de água disponível, onde são apresentados os valores de umidade e tensões de água no solo, obtidos nos ensaios com a coluna de areia e a câmara de pressão de Richards. Estes resultados mostram que a adição destes polímeros hidroretentores influenciam positivamente na infiltração e armazenamento da água no solo.

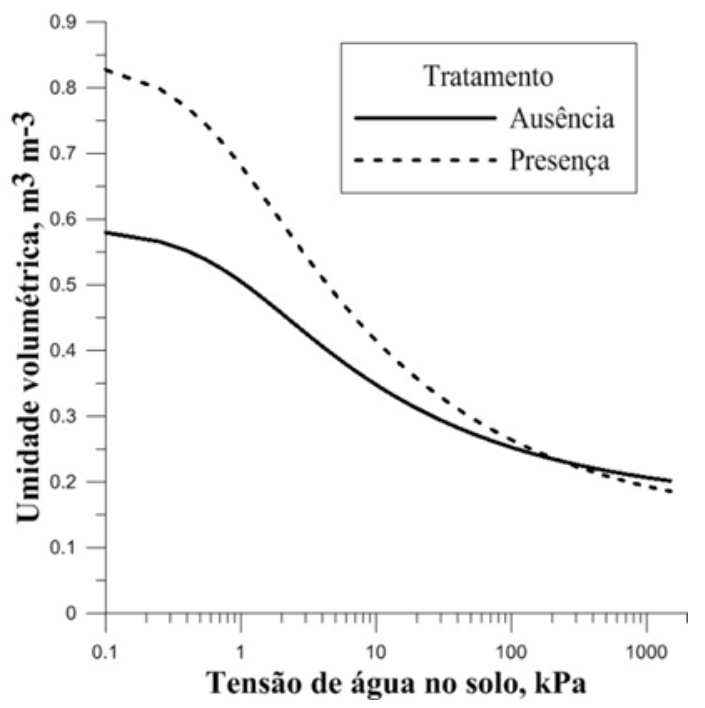

Figura 2. Curva de retenção de água no solo com a ausência $\left(0 \mathrm{~g} \mathrm{~L}^{-1}\right)$ e a presença de hidrogel $\left(3 \mathrm{~g} \mathrm{~L}^{-1}\right)$, submetidos as tensões $1,6,10,33$ e 100, 500, 1000 e $1500 \mathrm{kPa}$.

Figure 2. Water retention curve in the soil, the absence $\left(0 \mathrm{~g} \mathrm{~L}^{-1}\right)$ and the presence of hydrogel $\left(3 \mathrm{~g} \mathrm{~L}^{-1}\right)$, subjected tensions $1,6,10,33$ and $100,500,1000$ and $1500 \mathrm{kPa}$. 
Estes resultados corroboram com o descrito por Navroski et al. (2015),onde afirmam que o uso de hidrogel possibilita redução da irrigação em mudas de Eucalyptus dunnii Maiden, aumentando a capacidade de retenção de água, em todas as colunas de sucções avaliadas, sendo que houve um aumento da retenção com o hidrogel adicionado ao substrato.

Conforme Rezende (2001), isso pode ser explicado devido ao polímero apresentar mais de $60 \%$ dos grânulos com diâmetro inferior a $1,0 \mathrm{~mm}$. O mesmo autor cita que no estudo da influência da granulometria do polímero hidroabsorvente na retenção de água, concluiu que o diâmetro dos grânulos é de extrema importância na retenção da água. Segundo Prevedello e Loyola (2007), o hidrogel tem capacidade de absorver 150 a 400 vezes sua massa seca, pode ser utilizado para aumentar a capacidade de armazenamento de água, minimizando os problemas associados à disponibilidade irregular ou deficitária de água e má estruturação, sendo uma alternativa para a baixa disponibilidade de água no solo, quando esta puder afetar de forma negativa o desenvolvimento das plantas.

\section{CONCLUSÃO}

- O hidrogel proporciona o aumento na retenção de água no solo, possibilitando o retardamento de todos os sintomas de déficit hídrico avaliados.

- O hidrogel apresenta maior influência quando a irrigação é efetuada em menor frequência, sendo uma alternativa para plantios em épocas secas do ano.

- A aplicação deste polímero no plantio, apresentou os maiores resultados para biomassa seca, teores de clorofila e trocas gasosas.

\section{REFERÊNCIAS}

AGABA, H.; LAWRENCE, J. B. O.; OBUA, J.; KABASA, J. D.; WORBES, M.; HÜTTERMANN, A. Hydrogel amendment to sandy soil reduces irrigation frequency and improves the biomass of Agrostis stolonifera. Agricultural Sciences, Coulterville, v. 2, n. 4, p. 544 - 550, 2011.

AZEVEDO, T. L. F. Avaliação da eficiência do polímero agrícola de poliacrilamida no fornecimento de água para o cafeeiro (Coffea arabica L) cv. Tupi. 38 f. Dissertação (Mestrado em Agronomia) -Universidade Estadual de Maringá, Maringá, 2000.

BLAKE, G. R.; HARTGE, K. H. Bulk density. In: KLUTE, A. (Ed.) Methods of soil analysis: physical and mineralogical methods. Madison: American Society of Agronomy, Soil Science Society of America, 2 ed. 1986, $375 \mathrm{p}$.

BUTCHER, P.; SKINNER, A.; GARDINER, C. Increased inbreeding and interspecies gene flow in remnant populations of the rare Eucalyptus benthamii. Genetics, Rockville, v. 6, n. 2, p. 213 - 226, 2005.

BUZETTO, F. A.; BIZON, J. M. C.; SEIXAS, F. Avaliação de polímero adsorvente à base de acrilamida no fornecimento de água para mudas de Eucalyptus urophylla em pós-plantio. 2002. Disponível em: http://www.ipef.br/publicacoes/ctecnica/nr195.pdf>. Acesso em: 07 agosto 2015.

FOOD AND AGRICULTURE ORGANIZATION OF THE UNITED NATIONS (FAO). Forest \& Landscape Denmark - FLD. INTERNATIONAL PLANT GENETIC RESOURCES INSTITUTE (IPGRI). Forest genetic resources conservation and management. Rome: International Plant Genetic Resources Institute; 2004.

DAVIDE, A. C.; FARIA, J. M. R. Viveiros florestais. In: DAVIDE, A. C.; SILVA, E. A. A. Produção de sementes e mudas de espécies florestais. Lavras: Universidade Federal de Lavras, 2008, 124 p.

FAO, FLD, IPGRI. Forest genetic resources conservation and management. Rome: International Plant Genetic Resources Institute, 2004. 94 p.

HAASE, D. Understanding forest seedling quality: measurements and interpretation. Tree Planter's Notes. United States: Department of Agriculture. Forest Service, Washington, v. 52, n. 2, p. 24 - 30, 2008.

HIGA, R. C. V.; PEREIRA J. C. D. Usos potenciais do Eucalyptus benthamii Maiden et Cambage. Comunicado Técnico. Colombo: Embrapa Florestas, 2003.

INDÚSTRIA BRASILEIRA DE ÁRVORES (IBÁ). Relatório IBÁ 2015. Disponível em: <http://www.iba.org/ images/shared/iba_2015.pdf. Acesso em 26 ago.2015.

KLUTE, A. Water retention: Laboratory methods. In: KLUTE, A. Methods of soil analysis: physical and

FLORESTA, Curitiba, PR, v. 46, n. 2, p. 215 - 225, abr. / jun. 2016.

Felippe, D. et al.

ISSN eletrônico 1982-4688

DOI: $10.5380 /$ rf.v46i2.43920 
mineralogical methods. 2 ed. Madison: American Society of Agronomy, Soil Science Society of America, 1986, 660 p.

LAMBERS, H.; CHAPIN, F. S.; PONS, T. L. Plant physiological ecology. Springer, New York, 2008,591 p.

LARCHER, W. Ecofisiologia vegetal. Tradução: Prado, C. H. B. A. São Carlos: Ed. Rima, 2006, 531 p.

LEITE, F. P. Crescimento, relações hídricas, nutricionais e luminicas em povoamnetos de Eucalyptus grandis em diferentes densidades populacionais. 90 f. Dissertação (Mestrado em solos e Nutrição de plantas) Universidade Federal de Viçosa, Viçosa, 1996.

LOPES, J. L. W.; SILVA, M. R.; SAAD, J. C. C.; ANGÉLICO, T. S. Uso de hidrogel na sobrevivência de mudas de Eucalyptus urograndis produzidas com diferentes substratos e manejos hídricos. Ciência Florestal, Santa Maria, v. 20, p. 217 - 224, 2010.

MAESTRI, R. Modelo de crescimento e produção para povoamentos clonais de Eucalyptus grandis considerando variáveis ambientais. $143 \mathrm{f}$. Tese (Doutorado em Engenharia Florestal) - Universidade Federal do Paraná, Curitiba, 2003.

NAVROSKI, M. C.; ARAÚJO, M. M.; FIOR, C. S.; CUNHA, S. F.; BERGHETTI, A. L. P.; PEREIRA, M. O. Uso de hidrogel possibilita redução da irrigação e melhora o crescimento inicial de mudas de Eucalyptus dunnii Maiden. Scientia Forestalis. Piracicaba, v. 43, n. 106, p. 467 - 476, 2015.

NAVROSKI, M. C.; ARAÚJO, M. M.; REININGER, L. R. S.; MUNIZ, M. F. B.; PEREIRA, M. O. Influência do hidrogel no crescimento e no teor de nutrientes das mudas de Eucalyptus dunnii. Floresta, Curitiba, v. 45, n. 2, p. $315-328,2015$.

NAVROSKI, M. C.; ARAÚJO, M. M.; CUNHA, F. S.; BERGHETTI, A. L. P.; PEREIRA, M. O. Influência do polímero hidroretentor na sobrevivência de mudas de Eucalyptus dunnii sob diferentes manejos hídricos. Revista Nativa, Sinop, v. 2, n. 2, p. 108 - 113, 2014.

NICOLETTI, M. F; NAVROSKI, M. C.; ANDRIOLLO, K.; PEREIRA, M. O.; FRIGOTTO, T. Efeito do hidrogel no enraizamento e crescimento inicial de miniestaca do híbrido Eucalyptus urograndis. Cultivando o Saber, Cascavel, v. 7, n. 4, p. 353 - 361, 2014.

NISGOSKI, S.; MUNIZ, G. I. B.; KLOCK, U. Caracterização anatômica da madeira de Eucalyptus benthamii Mainden et Cambage. Ciência Florestal, Santa Maria, v. 8, n. 1, p. 76, 1998.

NUNES, C. M. J. Caracterização da resposta ao déficit hídrico de linhas transgênicas de Medicago trunculata cv. Jemalong. 64 f. Dissertação (Mestrado em Biologia Celular e Biotecnologia), Universidade de Lisboa, Lisboa - Portugal, 2007.

PREVEDELLO, C. L.; LOYOLA, J. M. T. Efeito de polímeros hidroretentores na infiltração da água no solo. Scientia Agraria, Curitiba, v. 8, n. 3, p. 313 - 317, 2007.

REINERT, D. J.; REICHERT, J. M. Coluna de areia para medir a retenção de água no solo: protótipos e testes. Ciência Rural, Santa Maria, v. 36, p. 1931 - 1935, 2006.

SANT' ANNA, H. L. S. Aspectos fisiológicos de variedades de citros submetidas à deficiência hídrica progressiva. 84 f. Dissertação (Mestrado em Fitotecnia) - Curso de Pós-Graduação em Ciências Agrárias, Universidade Federal do Recôncavo da Bahia, Cruz das Almas, 2009.

SERRAJ, R.; SINCLAIR, R. T. Osmolyte accumulation: can it really help increase crop yield under drought conditions? Plant Cell Environnmental, v. 25, p. 333 - 341, 2002.

SILVA, M. R. Caracterização morfológica, fisiológica e nutricional de mudas de Eucalyptus grandis W. (HILL ex MAIDEN) submetidas a diferentes níveis de estresse hídrico durante a fase de rustificação. 105 f. Dissertação (Mestrado em Ciências Agrárias) - Universidade Federal do Paraná, Curitiba, 1998.

SOUZA, R. P.; MACHADO, E. C.; SIlVA, J. A. B.; LAGOA, A. M. M. A.; SILVEIRA, J. A. G. Photosynthetic gas exchange, chlorophyll fluorescence and some associated metabolic changes in cowpea (Vignaun guiculata) during water stress and recovery. Environmental and Experimental Botany, n. 51 , p. 45 56, 2004.

TAYLOR, K. C.; HALFACRE, R. G. The effect of hydrophylic polymer on media water retention and nutrient availability to Ligustrum lucidum. Horticulture Science, Czech Republic, v. 21, n. 5, p. 1159 - 1161, 1986.

THOMAS, D. S. Hidrogel applied to the root plug off subtropical eucalypt seedlings halves transplant death 
following planting. Forest Ecology and Management, New Brunswick, n. 255, p. 1305 - 1314, 2008.

TOHIDI, M. H. R.; SHIRANI, R. A. H.; NOUR, M.; HABIBI, D.; MODARRES S. A. M.; MASHHADI M, A, B.; DOLATABADIAN, A. Response of six oilseed rape genotypes to water stress and hydrogel application. Pesquisa Agropecuária Tropical, Goiânia, v. 39, n. 3, p. 243 - 250, 2009.

VAN GENUCHTEN, M. T. A closed-form equation for predicting the hydraulic conductivity of unsaturated soils. Soil Science Society of America Journal, Madison, v. 44, p. 892 - 898, 1980.

WENDLING, I.; DUTRA, L. F. Produção de mudas de eucalipto por estaquia e miniestaquia. In: WENDLING, I.; DUTRA, L. F. Produção de mudas de eucalipto. Colombo: Embrapa Florestas, 2010. cap. 2, p. 50 - 80. 